Published in International Journal of Bilingualism (2015; OnlineFirst).

DOI:10.1177/1367006915573338

\title{
The Early Learning of Interlingual Correspondence Rules in Receptive Multilingualism
}

\author{
Jan Vanhove \\ University of Fribourg, Department of Multilingualism \\ Rue de Rome 1, CH-1700 Fribourg, Switzerland \\ jan.vanhove@unifr.ch
}

Aims and objectives. This article investigates whether learners are able to quickly discover simple, systematic graphemic correspondence rules between their L1 and an unknown but closely related language in a setting of receptive multilingualism.

Design. Eighty L1 German speakers participated in a translation task with written Dutch words, most of which had a German cognate. In the first part of the translation task, participants were shown 48 Dutch words, among which either ten cognates containing the digraph 〈oe〉 (always corresponding to a German word with $\langle\mathrm{u}\rangle$ ) or ten cognates with the digraph $\langle\mathrm{ij}\rangle$ (corresponding to German 〈ei ). During this part, participants were given feedback in the form of the correct translation. In the second (feedback-free) part of the task, participants were shown another 150 Dutch words, among which 21 cognates with 〈oe〉 and 21 cognates with 〈ij〉.

Data and analysis. The participants' German translations of 〈oe〉 and 〈ij〉 cognates in the second part were coded for the presence of $\langle\mathrm{u}\rangle$ and 〈ei〉, respectively. The data were then analyzed in generalized linear mixed models. Data and R code are available online.

Findings. Participants who encountered 〈oe $\rangle$ or $\langle\mathrm{ij}\rangle$ cognates in the first part were more likely to translate 〈oe $\rangle$ or $\langle\mathrm{ij}\rangle$ cognates using German words containing 〈 $\mathrm{u}\rangle$ or 〈ei , respectively, in the second part compared to their respective controls, suggesting that correspondence rule learning had taken place. Learning effects during the second part, i.e., in the absence of explicit feedback, were more modest.

Originality. This study provides the first direct experimental evidence of interlingual correspondence rule learning during a receptive multilingualism task.

Significance. These findings pave the way towards investigations of the learning of more complex, less systematic correspondence rules that are nonetheless of great importance in receptive multilingualism.

Keywords: cognates, induction, intercomprehension, interlingual correspondence rules, linguistic distance, receptive multilingualism, rule learning 


\section{Introduction}

\section{Cognate relationships and interlingual correspondence rules}

Formal similarities to known languages greatly facilitate the learning of a new language (Ringbom, 2007). An important source of such helpful cross-linguistic similarities is provided by COGNATES (Carton, 1971; Cummins, 2010; de Groot \& Keijzer, 2000; Haastrup, 1991; Lotto \& de Groot, 1998; Rubin, 1975). For present purposes, these are defined as historically related words in different language varieties that are translation equivalents in at least one sense. This definition includes word pairs sharing a common root in an ancestor language, such as German Apfel and English apple (from Germanic), as well as loan words, such as sauna in several languages (from Finnish). In addition to being useful in foreign language learning, cognate relationships between closely related languages can be so pervasive and easily perceived that they give rise to RECEPTIVE MULTILINGUALISM. This is a constellation in which readers or listeners are able to (partially) understand a language variety without ever having learned or acquired it (Braunmüller \& Zeevaert, 2001). Receptive multilingualism thanks to linguistic relatedness is found, to a greater or lesser extent, in Scandinavia (e.g., Elert, 1981), between Portuguese and Spanish (e.g., Jensen, 1989) and between Dutch and German (e.g., Gooskens, Kürschner, \& van Bezooijen, 2011), to mention but a few examples.

The mere presence of cognate relationships does not guarantee that readers or listeners can identify and make use of them. The successful recognition of cognates in a related but unknown language (Lx) depends both on reader- or listener-related variables - including the size and make-up of their linguistic repertoires (e.g., Berthele, 2011; Gooskens et al., 2011; Singleton \& Little, 1984; Vanhove \& Berthele, 2015b) - and cognate-related characteristics. Of specific importance for the present study, successful Lx cognate recognition depends to a large extent on the cognates' degree of orthographic or phonetic overlap with their counterparts in the L1 or another known language: the less overlap, the poorer cognate recognition (e.g., Berthele, 2011; Gooskens et al., 2011; Kürschner, Gooskens, \& van Bezooijen, 2008; van Bezooijen \& Gooskens, 2005; Vanhove \& Berthele, 2015a).

That said, formal discrepancies between cognates in closely related languages are often non-random (i.e., rule-based) from a synchronic perspective. A first source of such rule-based 
discrepancies are diachronic sound changes, which may or may not be reflected in the cognates' spelling. Examples include the affricatization of voiceless plosives in initial position in the High German consonant shift (e.g., Dutch paard - German Pferd 'horse') and Spanish vowel breaking (e.g., Italian porta - Spanish puerta 'door'). A second source are differences in arbitrary phoneme-grapheme mappings. For instance, the $[\mathrm{u}]$ sound is typically rendered as $u$ in German (Buch), as $o$ in Swedish (bok), and as oe in Dutch (boek 'book'). When listeners or readers are familiar with such CORRESPONDENCE RULES between the target and source languages, their comprehension of Lx cognates to which these correspondences apply should be hampered less by sheer formal discrepancies.

In the context of listening comprehension, it is typically assumed that listeners engaging in receptive multilingualism gradually pick up on the relevant correspondence rules (Bannert, 1981; Warter, 2001). For instance, Haugen (1981) estimates that speakers of Norwegian would need about two weeks to habituate to the sound system of the closely related North-Germanic language Danish. To my knowledge, though, such estimates have not yet been elevated from the realm of anecdotal observation. In the context of Lx reading, a computer-based study by Möller (2007) suggests that "by far the majority of Dutch vocabulary is accessible for German readers, if they are familiar with a small set of sound correspondences" (p. 302) such as those brought about by the High German consonant shift. Correspondingly, imparting awareness of interlingual correspondence rules is a key aim of learning materials that strive to foster receptive multilingualism skills (e.g., Hufeisen \& Marx, 2007; Klein \& Stegmann, 2000).

Despite such applied interest in receptive multilingualism, the learning of interlingual correspondence rules is very much a blank spot in terms of empirical research. What little research exists on interlingual correspondence rule learning focuses on the effects of explicit instruction. Hedquist (1985, cited in Bergsma, Swarte, \& Gooskens, 2014) observed substantial improvements in the receptive Swedish skills of Dutch-speaking participants after ten hours of instruction in lexical, phonological and orthographic differences between Dutch and Swedish. More recently, Bergsma et al. (2014) taught twelve Dutch-speaking 11- to 12-year-olds the eight most common Frisian-Dutch sound correspondences for 50 minutes but observed no measurable improvement in receptive listening skills in Frisian compared to a control group. 
The present study: Correspondence rule learning with and without explicit feedback

While intervention studies like Hedquist's and Bergsma et al.'s remain a desideratum in multilingualism pedagogy, what is of interest in this article is not whether explicit instruction in interlingual correspondence rules improves receptive multilingualism skills. Rather, the goal of this study was to investigate whether participants can discover systematic interlingual correspondences themselves during the early stages of receptive multilingualism without being explicitly taught the relevant rules.

Simple and systematic correspondences. As a first step, I focus on the learning of simple, systematic graphemic correspondences during a reductionistic receptive multilingualism task. Specifically, I investigated whether German-speaking students without prior knowledge of the closely related Germanic language Dutch are able to identify the correspondence rules 'Dutch $\langle\mathrm{ij}\rangle=$ German $\langle\mathrm{ei}\rangle$ ' and 'Dutch $\langle\mathrm{oe}\rangle=$ German $\langle\mathrm{u}\rangle$ ' when translating Dutch cognates into German and then apply these correspondence rules to new stimuli. ${ }^{1}$ The Dutch digraph 〈ij > is unknown in German and represents the [ci] diphthong; the digraph 〈oe〉 is an alternative spelling of 〈ö〉 in German (representing [ø]) but is the typical Dutch representation of [u]. Note that the aim of the study was not to find out whether it is the $\langle\mathrm{oe}\rangle-\langle\mathrm{u}\rangle$ or the $\langle\mathrm{ij}\rangle-\langle\mathrm{ei}\rangle$ rule that is easier to learn. As will be discussed in detail in the Method section, the study's use of two correspondence rules, rather than just one, allowed for an experimental design in which each of the experimental groups (〈oe $\rangle-\langle\mathrm{u}\rangle$ and $\langle\mathrm{ij}\rangle-\langle\mathrm{ei}\rangle)$ doubled as the other's control group (no $\langle\mathrm{ij}\rangle-\langle\mathrm{ei}\rangle$ and no $\langle\mathrm{oe}\rangle-\langle\mathrm{u}\rangle$, respectively).

The $\langle\mathrm{oe}\rangle-\langle\mathrm{u}\rangle$ and $\langle\mathrm{ij}\rangle-\langle\mathrm{ei}\rangle$ correspondences were chosen for the following reasons. First, they are simple in that they do not depend on, for instance, the graphemes' phonological context or position within the word. Second, a reasonably large number of Dutch-German cognates are characterized by these correspondences so that it was comparatively easy to design a translation task in which the rules were systematic, i.e., applied without exception. The simplicity and systematicity of these two correspondence rules is obviously a far cry from most actual interlingual correspondence rules, which are often context-dependent and irregular from a synchronic perspective. But by investigating simple and systematic correspondences first, we can calibrate our expectations about learning more complex and less systematic correspondences: if 
the paradigm employed in the present study does not lead to learning success for simple and systematic correspondences, it cannot be expected to give rise to learning effects for more complex and less systematic rules.

On corpus reliability in cognate translation tasks. In most receptive multilingualism studies using cognate translation tasks to date, the participants are not told whether their translations are correct or not. This likely lessens the odds that they will learn recurring interlingual correspondences in the course of the task. To elaborate, according to Schmidt's (1990) Noticing Hypothesis, the conversion of input to intake requires noticing on the part of the learner. By their nature, however, interlingual correspondence rules can only be noticed if the learner can first link Lx input to the corresponding L1 (L2, .., Ln) items. Concretely, the $\langle\mathrm{Oe}\rangle-\langle\mathrm{u}\rangle$ correspondence in moeder-Mutter 'mother' can only serve as the basis for (noticingbased) induction if the participants actually realize that the German counterpart of Dutch moeder is Mutter first, or if they (falsely) assume another translation equivalent with 〈u〉. If the link between the Lx word and an L1 (L2, .., Ln) counterpart is not established, the grapheme correspondence cannot be inferred. Thus, the basis for rule inferencing consists of the Lx stimuli in combination with their L1 $(\mathrm{L} 2, \ldots, \mathrm{Ln})$ counterparts - not of the bare Lx stimuli. If the participants have to guess these counterparts (unconstrained by context) and do not receive feedback, the corpora consisting of 'Lx stimulus-L1 counterpart' pairs is only as reliable as the participants' guesses, and less reliable corpora are unlikely to be fertile ground for rule learning. Additionally, even if participants correctly guess that moeder translates as Mutter, they need not be entirely sure of this guess - especially in the absence of a constraining context - and the degree of certainty will likely differ between participants. Thus, the subjective reliability of the corpus of 'Lx stimulus-L1 counterpart' pairs will vary between participants, too.

Interindividual differences in actual or subjective corpus reliability can be assumed to increase interindividual differences in correspondence rule learning, potentially making it harder to separate the signal (rule learning), if present, from the noise (interindividual differences). To equate all participants in terms of the reliability of input, then, feedback was provided during the first part of the experiment (training) in the form of the correct translation after the translation attempt by the participant. This ensured that all participants within each learning condition had 
the same corpus of 'Lx stimulus-L1 counterpart' pairs to their disposal. During the second part (testing), no such feedback was provided. This also permitted an investigation into learning effects given a corpus of lesser reliability, i.e., one based on the participants' own best guesses.

Research questions. To recap, the two research questions were addressed:

1. Can simple, systematic interlingual correspondence rules be learned in the course of a receptive multilingualism task when explicit feedback in the form of the stimuli's translations is provided?

2. Can such correspondence rules be learned when no such explicit feedback is provided?

The working assumption throughout was that when participants have learned the $\langle\mathrm{oe}\rangle-\langle\mathrm{u}\rangle$ or $\langle\mathrm{ij}\rangle-\langle e \mathrm{e}\rangle$ rule, they would be more likely to translate Dutch words featuring 〈oe〉 or $\langle\mathrm{ij}\rangle$ with German words featuring 〈u〉 or 〈ei〉, respectively. This, in turn, would lead to better translation performance.

\section{Method}

\section{Participants}

Eighty German-speaking students (14 men; mean age 22 years), most of them studying at the University of Fribourg (Switzerland), were recruited by means of posters, announcements, and word of mouth. None of them were linguistics or language majors. None of participants reported competences in Germanic languages besides standard German, German dialects, and English. Participants completed a brief web-based questionnaire (age, sex, study program, languages known), a computer-run learning experiment in the form of a translation task, and three paper-and-pencil vocabulary tests. For the learning experiment, they were randomly assigned to one of two learning conditions ( $\langle\mathrm{ij}\rangle-\langle\mathrm{ei}\rangle$ and $\langle\mathrm{oe}\rangle-\langle\mathrm{u}\rangle)$ that doubled as each other's control condition as well as to one of two list orders (see below). They were paid for their participation.

\section{Language proficiency data}

Previous research has highlighted that performance on cognate translation tasks depends in part on the size and make-up of the participants' linguistic repertoires. Of specific interest, 
translation accuracy has been found to correlate positively with the participants' vocabulary knowledge in a related L1 as well as with their foreign language proficiency (e.g., Berthele, 2011; Singleton \& Little, 1984; Vanhove \& Berthele, 2015b). While the impact of L1 and foreign language proficiency is not the focus of the present study, language proficiency data were nevertheless collected in order to allow bringing a known source of interindividual differences under statistical control, thereby increasing statistical power.

To this end, participants were asked to list the languages they knew and completed French and English vocabulary tests for advanced learners (LexTALE; Lemhöfer \& Broersma, 2012, and Brysbaert, 2013, respectively) as well as an advanced German vocabulary test for native speakers (WST; Schmidt \& Metzler, 1992). On average (mean), participants knew 2.9 (living) languages other than German and German dialects, had English and French LexTALE scores of 0.67 and 0.59 (where 1 is a perfect score and 0.50 corresponds to chance performance), respectively, and a WST score of 33 out of 42 . The means and standard deviations split up according to learning condition are presented in Table 1.

Table 1. Demographic and language-proficiency variables according to learning condition.

\begin{tabular}{lll}
\hline Variable & $\begin{array}{l}\langle\mathrm{ij}\rangle \text { - } \mathrm{i} \text { (ei Learning Condition } \\
(43 \text { participants })\end{array}$ & $\begin{array}{l}\langle\mathrm{oe}\rangle \text {-〈u } \\
(37 \text { participants })\end{array}$ \\
\hline Women / Men & $35 / 8$ & $31 / 6$ \\
Age (mean (SD)) & $22(1)$ & $22(3)$ \\
German vocabulary test (mean (SD)) & $33(3)$ & $32(3)$ \\
LexTALE English (mean (SD)) & $0.68(0.08)$ & $0.66(0.08)$ \\
LexTALE French (mean (SD)) & $0.61(0.09)$ & $0.57(0.08)$ \\
Number of languages (mean (SD)) & $3.0(0.8)$ & $2.7(0.6)$ \\
\hline
\end{tabular}

Learning experiment

The learning experiment was presented as a translation task. Participants sat in front of a laptop and were instructed that they would be shown written words in Dutch (a language they did not know but that is closely related to German), which they were asked to translate into German. If they had a translation suggestion, they could press the ' $\mathrm{J}$ ' key (marked with a green sticker as a memory support), after which a text-box would appear in which they could enter their German 
translation. They could also decline to suggest a translation by pressing the ' $F$ ' key (marked with a red sticker). After entering the translation or striking the ' $F$ ' key, feedback (during training, see below) or the next stimulus (during testing) appeared.

The first part of the translation task featured 48 stimuli and constituted the training block. In this block, participants received feedback: after entering their translation or pressing the ' $F$ ' key, the stimulus was shown once more with its model German translation shown underneath in green capital letters for 2.2 seconds. The following 150 stimuli constituted the three test blocks (50 stimuli per block) and were not followed by feedback. Participants had the option to take short self-timed breaks between blocks.

After completing the experiment, participants wrote down what they thought was the goal of the experiment. They were asked to be as specific as possible. The goal of this question slip was to find out how conspicuous the targeted correspondences were in the experiment.

Training stimuli. The training block consisted of 40 cognates (e.g., Du. knaap - Gm. Knabe 'lad') and eight non-cognates (e.g., Du. misschien - Gm. vielleicht 'perhaps'). The noncognates were included for two reasons. First, since their meaning cannot be guessed correctly from their formal similarity to a known word, participants who are able to translate non-cognates can be identified as having some limited degree of prior lexical knowledge of Dutch. Second, including non-cognates ensures that participants will accept that some stimuli are simply untranslatable, rendering their responses more spontaneous and less far-fetched.

Thirty of the cognates and the six of the non-cognates served as fillers and were presented to all participants. The ten remaining cognates were the critical training items. These were characterized by a simple graphemic correspondence to their German counterparts. Fortythree participants were shown critical items with 〈ij〉, which corresponded to 〈ei〉 in the German model translations (e.g., Du. twijfel - Gm. Zweifel 'doubt'); the other 37 participants were shown critical items with 〈oe〉, which corresponded to German 〈u〉 (e.g., Du. bezoek - Gm. Besuch 'visit'). Note that, in order to prevent ceiling effects, these stimuli did not differ from their German counterparts in this respect alone, as shown in the examples. The assignment of participants to either type of critical items (learning condition) was done at random by the computer, hence the uneven distribution. 
The $\langle\mathrm{ij}\rangle-\langle\mathrm{ei}\rangle$ and $\langle\mathrm{oe}\rangle-\langle\mathrm{u}\rangle$ correspondences were simple and systematic in that they were invariant with respect to their position within the word, surrounding phonemes or graphemes etc., applied without exception, and were bidirectional throughout the task: if (and only if) a cognate featured 〈ij〉 or 〈oe〉, its model translation featured 〈ei these correspondence rules do not apply as systematically (e.g., Du. groen - Gm. grün 'green'; Du. grijnzen - Gm. grinsen 'to grin'), but from the participants' point of view, this is irrelevant.

The critical training items were chosen to be maximally comparable between the two learning conditions. First, they were similar in terms of the corpus frequency of their German model translations. Corpus frequencies were extracted from the SUBTLEX-DE database (Brysbaert et al., 2011). The mean Zipf values were 4.8 for both sets. ${ }^{2}$ Second, the graphemic distance between the stimuli and their model translations, quantified by means of the Levenshtein algorithm (see, e.g., van Bezooijen \& Gooskens, 2005; Vanhove \& Berthele, 2015a), was comparable across the two sets with a mean Levenshtein distance of 0.45 in both sets. ${ }^{3}$ Third, both sets contained four nouns, three verbs, and three adjectives, adverbs or determiners. Fourth, they were matched on the extent to which they showed other recurring Dutch-German correspondences that were not the object of this study. For instance, both sets had two instances of final schwa apocope, one instance of $\mathrm{a}\langle\mathrm{k}\rangle-\langle\mathrm{ch}\rangle$ correspondence etc.; see the stimulus list for details (available from http://dx.doi.org/10.6084/m9.figshare.1291191). Additionally, identical morphemes featuring 〈ij〉 and 〈oe〉 did not reoccur during the task (e.g., the frequent morpheme correspondence toe- - zu- only occurred in toegeven - zugeben 'to admit').

Lastly, the training block contained two non-cognates that, depending on the learning condition, featured 〈ij〉 or 〈oe〉 but could not be translated with a German cognate (e.g., Du. lelijk - Gm. hässlich 'ugly'; Du. snoep - Gm. Süssigkeiten 'sweets'). These stimuli were included in order to ensure that the presence of $\langle\mathrm{ij}\rangle$ or $\langle\mathrm{oe}\rangle$ did not provide any clues as to whether it had a German cognate.

Test stimuli. The test phase consisted of 150 stimuli, which were divided into three blocks of 50 stimuli each. Each block featured seven cognates with 〈ij〉, seven cognates with 〈oe〉, 30 cognate fillers, and six non-cognate fillers. Since the actual number of Dutch-German morpheme pairs with the $\langle\mathrm{ij}\rangle-\langle\mathrm{ei}\rangle$ or $\langle\mathrm{oe}\rangle-\langle\mathrm{u}\rangle$ correspondences is limited, two times four pseudo-words 
derived from existing cognates were added to stimulus list (e.g., Du. moenter (from monter) Gm. munter 'lively'; Du. brijd (from breed) - Gm. breit 'broad'). The 〈ij $\rangle-\langle\mathrm{ei}\rangle$ or $\langle\mathrm{oe}\rangle-\langle\mathrm{u}\rangle$ test cognates were comparable in terms of corpus frequency (mean Zipf values of 4.3 and 4.1, respectively) and Levenshtein distance to their German model translations (mean distance of 0.46 for both sets).

The order of presentation of the test stimuli (but not of the training stimuli) was reversed for about half of the participants. The assignment to a list order was random (38 participants to list A, 42 participants to list B).

Scoring. All translations were checked manually and rated as either correct or incorrect according to the same protocol as used by Vanhove and Berthele (2015b); this protocol is available from http://dx.doi.org/10.6084/m9.figshare.1291191. In 35 out of 15,840 cases, participants provided 'near-miss' translations, typically by providing the correct lemma but in the wrong tense or degree of comparison. The results reported in this article do not change appreciably when such translations are also scored as correct. Note that the reasonableness of the translations was not judged. For instance, translating Du. dik 'thick, fat' as Gm. dich 'you' is perfectly reasonable in light of the High German consonant shift (e.g., ik 'I' would have translated as $i c h$ ). Such translations were nevertheless scored as incorrect since it is well-nigh impossible to formulate workable a priori criteria for defining 'reasonableness' (Berthele \& Vanhove, 2014, Note 6).

Additionally, the effect of correspondence rule learning on translation accuracy is arguably an indirect one: its direct effect will be an increased propensity to apply the correspondence rule when providing cognate guessing. Consequently, for all responses to 〈ij〉 and 〈oe〉 cognates, I also coded whether the German translation suggestions featured the correct vowel graphemes (i.e., 〈ei〉 or 〈u〉, respectively). Note that this coding was done regardless of the correctness of the translations. For instance, translating Du. vlijtig 'diligent' as Gm. Freitag 'Friday' instead of the correct fleissig is incorrect but still shows that the 〈ij〉-<ei〉 rule has been applied correctly. 


\section{Method of analysis}

The binary translation and vowel accuracy data for $\langle\mathrm{oe}\rangle$ and $\langle\mathrm{ij}\rangle$ test cognates were modeled in generalized (logistic) mixed effects models (see Jaeger, 2008, for an introduction geared towards language researchers) using the lme4 package (Bates, Maechler, Bolker, \& Walker, 2014) for R (R Core Team, 2014). Following Barr, Levy, Scheepers, and Tily (2013), the significance of the fixed effects of interest was assessed by fitting a model with the fixed effect term and a maximal random effects structure (i.e., by-participant and by-item random intercepts and random slopes) and comparing it to a model without the fixed effect term by means of a likelihood ratio test. Effect sizes and their standard errors are reported in log-odds (see Jaeger, 2008).

None of the results reported in this article change appreciably when control covariates (language proficiency data, Levenshtein distances, and Zipf values) are entered into the statistical models. In the interest of simplicity, these covariates will therefore not be further considered. However, readers interested in the covariate-adjusted models can download the data and R code, which are freely available from http://dx.doi.org/10.6084/m9.figshare.1291191.

\section{Results}

\section{Translation accuracy on fillers cognates and non-cognates}

Across training and test trials, each participant saw 120 cognate fillers. On average (mean $\pm \mathrm{SD}),\langle\mathrm{ij}\rangle$ participants translated $69 \pm 8$ of them correctly, and 〈oe〉 participants $70 \pm 7$. Each participant also saw 26 non-cognates ( 8 during training, 18 during testing). Twelve participants were able to translate a single non-cognate stimulus correctly. However, six of them translated the stimulus trekken 'to pull' as wandern 'to hike' - an unintended but otherwise correct translation ('to hike' is a secondary meaning of trekken), undoubtedly due to Gm. Trekking 'trekking' or Eng. to trek (a loan from Afrikaans/Dutch). Thus, these successful translation attempts were cognate-based. Given the low success rate in non-cognate translation, no participants were excluded from the analysis on the grounds of having a priori lexical knowledge of Dutch. 
Learning effects with explicit feedback

The first research question was whether simple and systematic interlingual correspondence rules ( $\langle\mathrm{ij}\rangle-\langle\mathrm{ei}\rangle$ and $\langle\mathrm{oe}\rangle-\langle\mathrm{u}\rangle)$ can be learned in the course of the cognate translation task when reliable input (in the form of stimulus-translation pairs) is provided in the training phase. This was firstly assessed by investigating the vowels in the responses to subsequent test trials exhibiting these correspondences. Table 2 and Figure 1 show the participants' average vowel choice accuracy according to learning condition and cognate category and indeed reveal a learning effect: $\langle\mathrm{ij}\rangle$ participants applied the $\langle\mathrm{ij}\rangle-\langle\mathrm{ei}\rangle$ correspondence rule correctly more often than did 〈oe〉 participants, and vice versa. ${ }^{4}$

Table 2. Mean percentage (with its standard deviation between brackets) of correct vowel choices (i.e., 〈u〉 for 〈oe〉 cognates and 〈ei〉 for 〈ij〉 cognates) per participant per cognate category (test items only).

\begin{tabular}{lll}
\hline Cognate Category & $\begin{array}{l}\text { (ij)-<ei〉 Learning Condition } \\
\text { (43 participants) }\end{array}$ & $\begin{array}{l}\langle\mathrm{oe}\rangle-\langle\mathrm{u}\rangle \text { Learning Condition } \\
(37 \text { participants })\end{array}$ \\
\hline 〈ij Cognates (21 items) & $44(22)$ & $29(16)$ \\
〈oe Cognates (21 items) & $30(16)$ & $43(17)$ \\
\hline
\end{tabular}




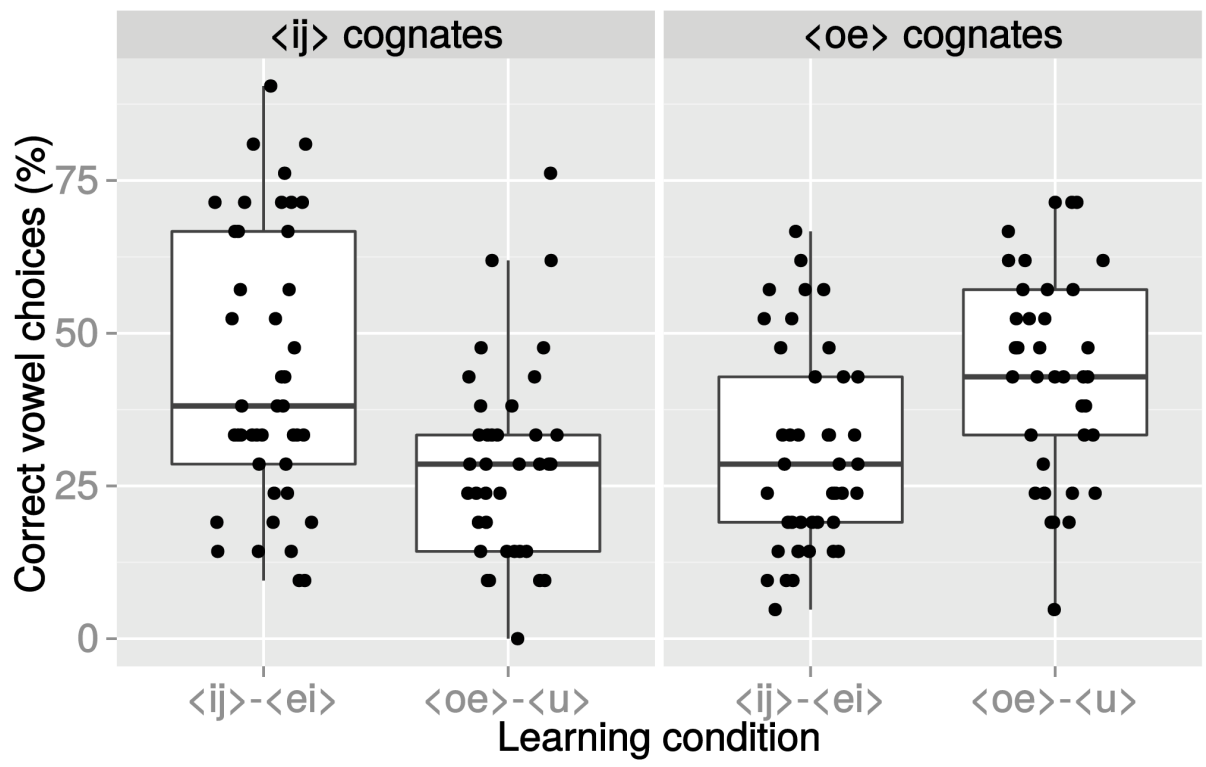

Figure 1. Vowel choice accuracy per participant for each cognate category ( $i j\rangle$ and $\langle o e\rangle$ ) and in each learning condition ( $\langle i j\rangle-\langle e i\rangle$ and $\langle o e\rangle-\langle u\rangle)$. Each dot represents a participant's vowel choice accuracy for a category of stimuli; the boxplots mark the quartiles of each distribution.

The interaction between learning condition and stimulus category was assessed by means of generalized linear mixed-effects models as described in the Method section. Only test cognates containing 〈ij〉 or 〈oe〉 were included in these models for a total of 42 stimuli $\times 80$ participants $=3,360$ responses. The modeled interaction was statistically significant according to a likelihood ratio test $\left(\chi_{L R}^{2}(1)=27.6, p<0.001\right)$, indicating that training items followed by explicit feedback induced more accurate vowel choices on test trials with the same correspondence. The effect size ( $\beta$ coefficient \pm standard error) of the interaction term was $1.9 \pm$ 0.3 log-odds.

An alternative - though more indirect - way of assessing whether learning took place is to compare the participants' translation accuracy proper. Vowel choice accuracy and translation accuracy were unsurprisingly strongly associated, however $(\varphi=0.91)$ : in only 140 cases did participants apply the correct correspondence rule without providing a correct translation. The interaction between learning condition and stimulus category was accordingly significant in 
terms of translation accuracy as well $\left(\chi^{2}{ }_{L R}(1)=21.2, p<0.001 ; \beta\right.$ of the interaction: $1.9 \pm 0.4 \log$ odds).

\section{Learning effects without explicit feedback}

The second question was whether participants in a cognate translation task can also discover simple, systematic correspondence rules in the absence of explicit feedback, i.e., during the test phase. The order of presentation varied between participants such that 38 participants were presented the stimuli as they appear in the Appendix, whereas this order was reversed for the other 42 participants. Learning effects in the absence of feedback would result in more accurate vowel choices (and, as a result, better translation performance) on stimuli with the untrained correspondence in Block 3 (last 50 trials) compared to Block 1 (first 50 trials): this would suggest that 〈oe $\rangle$ participants had discovered the $\langle\mathrm{ij}\rangle-\langle\mathrm{ei}\rangle$ rule and $\langle\mathrm{ij}\rangle$ participants the $\langle\mathrm{oe}\rangle-\langle\mathrm{u}\rangle$ rule in the course of the feedback-free part.

Table 3 and Figure 2 show the average percentage of correct vowel choices per stimulus split up between test blocks 1 and 3 (first and last 50 trials, respectively) for each cognate category. Of interest, $\langle\mathrm{ij}\rangle$ participants applied the $\langle\mathrm{oe}\rangle-\langle\mathrm{u}\rangle$ rule correctly slightly more often in Block 3 than in Block 1 and 〈oe〉 participants applied the $\langle\mathrm{ij}\rangle-\langle\mathrm{ei}\rangle$ rule correctly more often in Block 3 than in Block 1 as well. 
Table 3. Mean percentage (with standard deviation between brackets) of correct vowel choices per stimulus, split up between test blocks 1 and 3 (first and last 50 items).

\begin{tabular}{|c|c|c|c|c|}
\hline \multirow[t]{2}{*}{ Cognate Category } & \multicolumn{2}{|c|}{$\begin{array}{l}\langle\mathrm{ij}\rangle-\text {-ei }\rangle \text { Learning Condition } \\
\text { (43 participants) }\end{array}$} & \multicolumn{2}{|c|}{$\begin{array}{l}\langle 0 \mathrm{e}\rangle-\langle\mathrm{u}\rangle \text { Learning Condition } \\
\text { (37 participants) }\end{array}$} \\
\hline & Block 1 & Block 3 & Block 1 & Block 3 \\
\hline 〈ij $\rangle$ Cognates & $34(22)$ & $39(27)$ & $20(21)$ & $25(19)$ \\
\hline 〈oe〉 Cognates & $34(27)$ & $37(20)$ & $50(25)$ & $47(27)$ \\
\hline
\end{tabular}

Note: Each block contained 50 trials: six non-cognates, 30 cognate fillers, seven ‘oe〉 cognates, and seven 〈ij〉 cognates. The order of presentation varied between participants (orthogonally to learning condition) so that the items that appeared in Block 1 for 38 participants appeared in Block 3 for the other 42 participants. Block 2 is not shown as it contained the same stimuli for all participants.

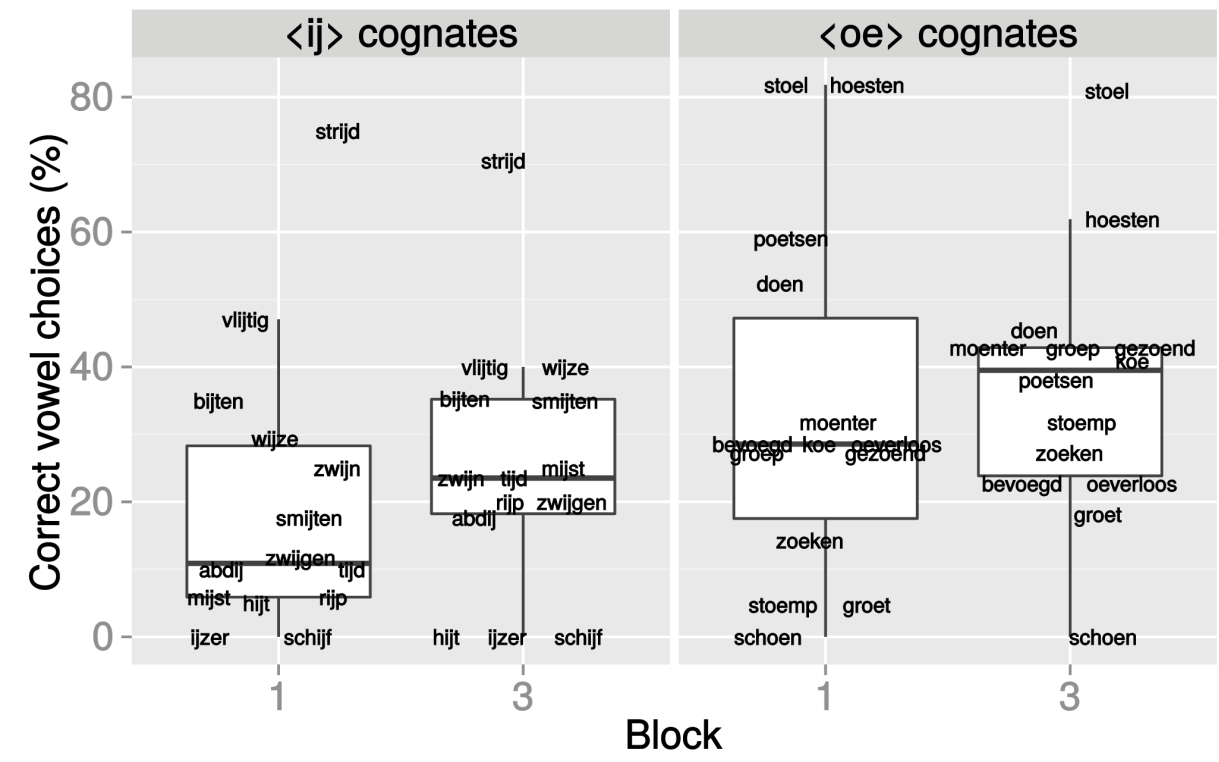

Figure 2. Percentage of correct vowel choices for each 〈ij〉 and 〈oe〉 cognate depending on whether it occurred in Block 1 or 3. The boxplots mark the quartiles of each distribution. Only answers on untrained correspondences were considered, i.e., 〈ij〉 cognates for 〈oe〉 participants and vice versa.

The effect of test block was fitted in a generalized (logistic) linear mixed-effects model. In this model, only test cognates with untrained correspondences (i.e., 〈ij> cognates for the <oe〉 
participants and vice versa) occurring in Blocks 1 and 3 were analyzed, for a total of 2 blocks per participant $\times 7$ stimuli per block per participant $\times 80$ participants $=1,120$ responses. Block 2 contained the same items for all participants and was not considered. The effect of Block on vowel choice accuracy was not consistently significant at the 0.05 threshold $\left(3.3<\chi_{L R}^{2}(1)<6.5\right.$, $0.01<p<0.07 ; \beta$ of the Block effect: $0.3 \pm 0.2$ log-odds). ${ }^{5}$

Alternatively, learning effects can be assessed by considering translation accuracy rather than vowel choice accuracy. The same trend of higher accuracy in Block 3 compared to Block 1 applied (cf. the high association between both dependent variables, $\varphi=0.91$ for these 1,120 responses, too), which was statistically significant according to a likelihood ratio test $(4.3<$ $\chi_{L R}^{2}(1)<12.3, p \mathrm{~s}<0.04 ; \beta$ of the Block effect: $0.4 \pm 0.2$ log-odds $)$.

Responses to post-experimental question slip

After the learning/translation task, participants were asked to write down what they thought the goal of the experiment was. Only eight out of 80 participants mentioned the $\langle\mathrm{ij}\rangle$ or $\langle o e\rangle$ sequences, and only four of them noted their correct counterparts $(3 \times\langle i j\rangle-\langle e i\rangle, 2 \times\langle o e\rangle-\langle u\rangle$; one participant mentioned both correspondences).

\section{Discussion and outlook}

This study sought to experimentally address the question whether participants engaging in a receptive multilingualism task can discover simple, systematic interlingual correspondences between an unknown but related language and their L1. When participants in a cognate translation task were given feedback in the form of the correct translation, learning effects could be established: participants who encountered ten instances of the Dutch-German graphemic correspondences $\langle\mathrm{ij}\rangle$-〈ei $\rangle$ or $\langle\mathrm{oe}\rangle-\langle\mathrm{u}\rangle$ outperformed those who were not on subsequent test trials. The learning effect showed itself both in terms of a higher propensity to apply the trained correspondence rule and in higher translation accuracy, but both of these aspects overlap to a high degree. Interestingly, only four out of 80 participants specified the $\langle\mathrm{ij}\rangle-\langle\mathrm{ei}\rangle$ or $\langle\mathrm{oe}\rangle-\langle\mathrm{u}\rangle$ rule on the post-experimental question slip. It thus seems that the learning effect cannot solely be attributed to the sheer conspicuousness of the correspondences within the experiment; in other words, the large number of filler items served their purpose. 
Additionally, this study investigated whether participants could discover systematic interlingual correspondences in the absence of explicit feedback. Cognates featuring previously untrained correspondences (i.e., ij〉 cognates for 〈oe〉 participants and vice versa) were translated using the applicable correspondence rule more often when they occurred in the last experimental block (i.e., after at least fourteen other instances of the rule) compared to when they occurred in the first experimental block. Correspondingly, such cognates were also translated correctly more often towards the end of the experiment. The results pertaining to feedback-free correspondence rule learning remain inconclusive, however, since their significance depended on how learning is operationalized (vowel choice accuracy vs. translation accuracy) and the specification of the statistical model (random-effects structure). What can be tentatively concluded, though, is that learning effects in the absence of feedback, however they are operationalized, are considerably weaker than in the presence of feedback (cf. the reported effect sizes).

It bears pointing out that participants only viewed ten training items with feedback, whereas by the time they began with the last block, they had already attempted to translate fourteen critical items. It thus seems that a corpus of fourteen Lx stimuli not accompanied by feedback is not as useful a basis for accurate rule-induction as a smaller but more reliable corpus of ten confirmed cognate pairs. Since participants either did not know the correct cognate translations or received no confirmation about their suspicions during the testing phase, these fourteen stimuli did not provide sufficiently reliable cues as to the interlingual correspondence rule. Possibly, larger stimulus sets or more transparent, less ambiguous stimuli could compensate for this lack of reliable cues.

All in all, the results of this learning experiment suggest that students are able to discover interlingual graphemic correspondence rules relatively quickly in the context of a receptive multilingualism task - provided the corpus of Lx-L1 cognates is highly reliable. The targeted correspondence rules were unnaturally simple and systematic, however, and a natural follow-up question is whether participants can also discover more complex and less systematic correspondences without instruction. For instance, the High German consonant shift gave rise to a series of Dutch-German cognates that are marked by the fricatization of post-vocalic voiceless plosives in German (e.g., Du. diep - Gm. tief 'deep', Du. straat - Gm. Strasse 'street'). These 
correspondences are both conditional (fricatization is position-dependent) and not entirely systematic from a synchronic perspective (e.g., Du. met - Gm. mit 'with', not miss; Du. lekGm. Leck 'leak', not Lech). Given how many cognate pairs are affected by the High German consonant shift (Möller, 2007), however, knowledge of such less-systematic synchronic correspondences would seem to be of the utmost importance for German-language learners of related Germanic languages.

In the case of the High German consonant shift, L1 German learners of other Germanic languages who are proficient in English may furthermore already have noted that similar correspondences apply between English-German cognates (cf. the English glosses of the examples throughout this article). Rather than having to learn the Dutch-German correspondences by induction, they could venture the guess that Dutch-German cognates are characterized by the same consonantal relationships as English-German cognates in a process labeled 'abduction' (Berthele, 2011). This could help them in spotting and applying the DutchGerman correspondence rules. Crucially, such an effect would have to apply even when Dutch words do not have English cognates. Additionally, the observable workings of the High German consonant shift are clusters of specific phoneme (or grapheme) correspondences such as $\mathrm{Du}$. /t, $\mathrm{p}, \mathrm{k} /$ - Gm. /s, f, x/. A psycholinguistically interesting question is whether instances of one such correspondence (e.g., /t/-/s/) increase the likelihood of the application of the other correspondences in the cluster (i.e., $/ \mathrm{p} /-/ \mathrm{f} /$ and $/ \mathrm{k} /-/ \mathrm{x} /$ ). It is these kinds of interlingual correspondence rule generalization that we will consider in more detail in our future investigations.

\section{Acknowledgments}

This study was financially supported by the Institute of Multilingualism, Fribourg, Switzerland. I thank Andrea Ender and Raphael Berthele for their useful comments on the design and write-up of this study.

\section{Notes}

${ }^{1}$ When considered as a language-learning intervention, the cognate translation task is perhaps best regarded as a form of inductive form-focused instruction in that the participants are to induce the interlingual correspondence rules themselves (Ellis, 2008, p. 882). Contrary to 
Hulstijn's (2005) definition of inductive learning, however, the rule is not mentioned in any way during the experiment (neither during training nor during testing).

${ }^{2}$ Van Heuven, Mandera, Keuleers, and Brysbaert (2014) proposed the Zipf scale as a word frequency scale that corresponds more closely to language users' perception of word frequency. In essence, the scale is a logarithmic expression of relative corpus frequency but with a correction for low-frequency items.

${ }^{3}$ The Levenshtein algorithm is used to compute the minimal number of insertions, deletions, and substitutions required to transform one string into another. For instance, Dutch bloem can be transformed into German Blume using a minimum of three operations (ignoring capitalization):

\begin{tabular}{|c|c|c|c|c|c|}
\hline $\mathrm{b}$ & 1 & $\mathrm{o}$ & $\mathrm{e}$ & $\mathrm{m}$ & \\
\hline $\mathrm{b}$ & 1 & $\mathrm{u}$ & & $\mathrm{m}$ & $\mathrm{e}$ \\
\hline & & Substitution & Deletion & & Insertion \\
\hline
\end{tabular}

Other alignments are possible but they all require at least three operations. This minimal number of operations is then normalized for the length of the strings, typically by dividing it by the length of the longest least-cost alignment (Heeringa, 2004, pp. 130-132) - in this case six, hence the Levenshtein distance of $3 / 6=0.50$.

${ }^{4}$ These percentages are low compared to the average translation success on filler cognates $(58 \%)$. However, the filler cognates (mean Levenshtein distance of 0.29 ) were chosen to be more transparent than the critical items (mean Levenshtein distance of 0.46 for both categories) in order not to discourage the participants.

${ }^{5}$ Following Barr et al. (2013), I first computed a mixed-effects model with a maximal random-effects structure, i.e., by-participant and by-item random intercepts as well as byparticipant and by-item random slopes for the Block effect. This model converged $\left(\chi_{L R}^{2}(1)=6.5\right.$, $p=0.01$ ), but with perfectly correlated random effects, indicating overparametrization. The model was therefore simplified by removing the correlation parameter between the random effects after recoding the Block variable as a sum-coded numerical variable (see Barr et al., 2013, Appendix; $\left.\chi^{2}{ }_{L R}(1)=3.4, p=0.07\right)$. Hence, a range of $\chi^{2}$ and $p$ values is reported. The reported effect size of the Block effect is the one associated with the model with the highest $p$ value. The same remarks apply when considering translation accuracy. 


\section{References}

Bannert, R. (1981). Referat av diskussionen i sektionen Talperceptionsforskning och nordisk hörförståelse. In Elert (Ed.), pp. 37-45.

Bates, D., Maechler, M., Bolker, B., \& Walker, S. (2014). lme4: Linear mixed-effects models using Eigen and S4. R package version 1.1-7. Available from http://CRAN.Rproject.org/package $=1 \mathrm{me} 4$.

Barr, D. J., Levy, R., Scheepers, C., \& Tily, H. J. (2013). Random effects structure for confirmatory hypothesis testing: Keep it maximal. Journal of Memory and Language, 68, 255-278.

Bergsma, F., Swarte, F., \& Gooskens, C. (2014). Does instruction about phonological correspondences contribute to the intelligibility of a related language? A study with speakers of Dutch learning Frisian. Dutch Journal of Applied Linguistics, 3, 45-61.

Berthele, R. (2011). On abduction in receptive multilingualism: Evidence from cognate guessing tasks. Applied Linguistics Review, 2, 191-219.

Berthele, R. \& Vanhove, J. (2014). Entre jeunes barbes et vieux de la vieille. Usages du répertoire plurilingue dans une tâche d'intercompréhension à travers les âges. Bulletin suisse de linguistique appliquée, 99, 31-50.

Braunmüller, K. \& Zeevaert, L. (2001). Semikommunikation, rezeptive Mehrsprachigkeit und verwandte Phänomene: Eine bibliographische Bestandsaufnahme. Arbeiten zur Mehrsprachigkeit/Working papers in multilingualism B-19, Sonderforschungsbereich 538 Mehrsprachigkeit. Hamburg, Germany: University of Hamburg.

Brysbaert, M. (2013). LexTALE_FR: A fast, free, and efficient test to measure language proficiency in French. Psychologica Belgica, 53, 23-37.

Brysbaert, M., Buchmeier, M., Conrad, M., Jacobs, A. M., Bölte, J., \& Böhl, A. (2011). The word frequency effect: A review of recent developments and implications for the choice of frequency estimates in German. Experimental Psychology, 58, 412-424. 
Carton, A. S. (1971). Inferencing: A process in using and learning language. In P. Pimsleur \& T. Quinn (Eds.), The psychology of second language learning: Papers from the Second International Congress of Applied Linguistics, Cambridge, 8-12 September 1969, pp. 4558. London: Cambridge University Press.

Cummins, J. (2010). Putting the evidence back into evidence-based policies for underachieving students. Strasbourg, France: Council of Europe.

de Groot, A. M. B. \& Keijzer, R. (2000). What is hard to learn is easy to forget: The roles of word concreteness, cognate status, and word frequency in foreign-language learning and forgetting. Language Learning, 50, 1-56.

Elert, C.-C. (Ed.) (1981). Internordisk språkförståelse. Föredrag och diskussioner vid ett symposium på Rungstegaard utanför Köpenhamn den 24-26 mars 1980. Umeå, Sweden: Umeå University.

Ellis, R. (2008). The study of second language acquisition (2nd ed.). Oxford: Oxford University Press.

Gooskens, C., Kürschner, S., \& van Bezooijen, R. (2011). Intelligibility of Standard German and Low German to speakers of Dutch. Dialectologia, Special issue, II, 35-63.

Haastrup, K. (1991). Lexical inferencing procedures or talking about words: Receptive procedures in foreign language learning with special reference to English. Tübingen: Gunter Narr.

Haugen, E. (1981). Skandinavisk som mellomspråk. Forskning og fremtid. In Elert (Ed.), pp. 121-143.

Hedquist, R. (1985). Nederländares förståelse av danska och svenska. Umeå, Sweden: Umeå University.

Heeringa, W. (2004). Measuring dialect pronunciation differences using Levenshtein distance. Ph.D. thesis, University of Groningen.

Hufeisen, B. \& Marx, N. (Eds.) (2014). EuroComGerm - Die sieben Siebe: Germanische Sprachen lesen lernen. 2nd edn. Aachen, Germany: Shaker. 
Hulstijn, J. H. (2005). Theoretical and empirical issues in the study of implicit and explicit second-language learning: Introduction. Studies in Second Language Acquisition, 27, 129-140.

Jaeger, T. F. (2008). Categorical data analysis: Away from ANOVAs (transformation or not) and towards logit mixed models. Journal of Memory and Language, 59, 434-446.

Jensen, J. B. (1989). On mutual intelligibility of Spanish and Portuguese. Hispania, 72, 848-852.

Klein, H. G. \& Stegmann, T. D. (Eds.) (2000). EuroComRom-Die sieben Siebe: Romanische Sprachen sofort lesen können. Aachen, Germany: Shaker.

Kürschner, S., Gooskens, C., \& van Bezooijen, R. (2008). Linguistic determinants of the intelligibility of Swedish words among Danes. International Journal of Humanities and Arts Computing, 2, 83-100.

Lemhöfer, K. \& Broersma, M. (2012). Introducing LexTALE: A quick and valid Lexical Test for Advanced Learners of English. Behavior Research Methods, 44, 325-343.

Lotto, L. \& de Groot, A. M. B. (1998). Effects of learning method and word type on acquiring vocabulary in a new language. Language Learning, 48, 31-69.

Möller, R. (2007). A computer-based exploration of the lexical possibilities of intercomprehension. Finding German cognates of Dutch words. In Jan D. ten Thije \& Ludger Zeevaert (Eds.), Receptive multilingualism. Linguistic analyses, language policies and didactic concepts, pp. 285-305. Amsterdam: John Benjamins.

R Core Team (2014). R: A language and environment for statistical computing. Software, version 3.1.2. Available from http://www.r-project.org/

Ringbom, H. (2007). Cross-linguistic similarity in foreign language learning. Clevedon, UK: Multilingual Matters.

Rubin, J. (1975). What the "good language learner" can teach us. TESOL Quarterly, 9, 41-51.

Schmidt, K.-H. \& Metzler, P. (1992). Wortschatztest (WST) [Vocabulary test]. Weinheim, Germany: Beltz Test.

Schmidt, R. W. (1990). The role of consciousness in second language learning. Applied Linguistics, 11, 129-158. 
Singleton, D. \& Little, D. (1984). A first encounter with Dutch: Perceived language distance and language transfer as factors in comprehension. In L. Mac Mathúna \& D. Singleton (Eds.), Language across cultures: Proceedings of a symposium held at St Patrick's College, Dublin, 8-9 July 1983, pp. 259-270. Dublin: Irish Association for Applied Linguistics.

van Bezooijen, R. \& Gooskens, C. (2005). How easy is it for speakers of Dutch to understand Frisian and Afrikaans, and why? Linguistics in the Netherlands, 22, 13-24.

van Heuven, W. J. B., Mandera, P., Keuleers, E., \& Brysbaert, M. (2014). SUBTLEX-UK: A new and improved word frequency database for British English. Quarterly Journal of Experimental Psychology, 67, 1176-1190.

Vanhove, J. \& Berthele, R. (2015a). Item-related determinants of cognate guessing in multilinguals. Accepted for publication in G. De Angelis, U. Jessner, \& M. Kresić (Eds.), Crosslinguistic influence and multilingualism.

Vanhove, J. \& Berthele, R. (2015b). The lifespan development of cognate guessing skills in an unknown related language. Accepted for publication in International Review of Applied Linguistics in Language Teaching.

Warter, P. (2001). Lexical identification and decoding strategies in interscandinavian communication. Arbeiten zur Mehrsprachigkeit/Working papers in multilingualism B-21, Sonderforschungsbereich 538 Mehrsprachigkeit. Hamburg, Germany: University of Hamburg.

\section{Appendix: Stimuli}

\section{Training stimuli}

$\langle i j\rangle$ and 〈oe〉 cognates

Participants in the $\langle\mathrm{ij}\rangle$-〈ei learning condition saw 〈ij〉 cognates; 〈oe〉 participants saw 〈oe〉 cognates. Levenshtein distances are rounded to two significant digits. Corpus frequencies were extracted from SUBTLEX-DE and are reported in Zipf units (van Heuven et al., 2014) to two significant digits. 


\begin{tabular}{|c|c|c|c|c|c|}
\hline Category & Stimulus & $\begin{array}{l}\text { German cognate } \\
\text { 'English translation' }\end{array}$ & $\begin{array}{l}\text { Levenshtein } \\
\text { distance }\end{array}$ & $\begin{array}{l}\text { Corpus } \\
\text { frequency } \\
\text { (Zipf) }\end{array}$ & $\begin{array}{l}\text { Other regular } \\
\text { correspondences }\end{array}$ \\
\hline$\langle\mathrm{ij}\rangle$ & mijn & mein 'my' & 0.33 & 6.4 & (none) \\
\hline$\langle\mathrm{ij}\rangle$ & wijd & weit 'wide' & 0.50 & 5.4 & $\mathrm{~d}-\mathrm{t}$ \\
\hline$\langle\mathrm{ij}\rangle$ & ijdel & eitel 'vain' & 0.50 & 3.2 & $\mathrm{~d}-\mathrm{t}$ \\
\hline$\langle\mathrm{ij}\rangle$ & zijde & Seite 'side' & 0.57 & 5.3 & $\mathrm{z}-\mathrm{s}, \mathrm{d}-\mathrm{t}$ \\
\hline$\langle\mathrm{ij}\rangle$ & lijk & Leiche 'corpse' & 0.57 & 4.8 & k-ch, schwa-Ø \\
\hline$\langle\mathrm{ij}\rangle$ & twijfel & Zweifel 'doubt' & 0.38 & 4.5 & $\mathrm{t}-\mathrm{z}$ \\
\hline$\langle\mathrm{ij}\rangle$ & mijl & Meile 'mile' & 0.43 & 4.0 & schwa-Ø \\
\hline$\langle\mathrm{ij}\rangle$ & blijven & bleiben 'to stay' & 0.38 & 5.6 & $\mathrm{v}-\mathrm{b}$ \\
\hline$\langle\mathrm{ij}\rangle$ & grijpen & greifen 'to grab' & 0.38 & 4.4 & $\mathrm{p}-\mathrm{f}$ \\
\hline$\langle\mathrm{ij}\rangle$ & rijden & reiten 'to ride' & 0.43 & 4.3 & $\mathrm{~d}-\mathrm{t}$ \\
\hline$\langle\mathrm{oe}\rangle$ & goed & gut 'good' & 0.60 & 6.5 & $\mathrm{~d}-\mathrm{t}$ \\
\hline$\langle\mathrm{oe}\rangle$ & genoeg & genug 'enough' & 0.29 & 5.6 & (none) \\
\hline$\langle\mathrm{oe}\rangle$ & moedig & mutig 'courageous' & 0.43 & 4.2 & $\mathrm{~d}-\mathrm{t}$ \\
\hline$\langle\mathrm{oe}\rangle$ & bloed & Blut 'blood' & 0.50 & 5.2 & $\mathrm{~d}-\mathrm{t}$ \\
\hline$\langle\mathrm{oe}\rangle$ & bezoek & Besuch 'visit' & 0.57 & 4.7 & $\mathrm{k}-\mathrm{ch}, \mathrm{z}-\mathrm{s}$ \\
\hline$\langle\mathrm{oe}\rangle$ & troep & Truppe 'troop' & 0.43 & 4.1 & schwa-Ø \\
\hline$\langle\mathrm{oe}\rangle$ & bloem & Blume 'flower' & 0.50 & 4.2 & schwa- $\varnothing$ \\
\hline$\langle\mathrm{oe}\rangle$ & roepen & rufen 'to shout' & 0.43 & 5.0 & $\mathrm{p}-\mathrm{f}$ \\
\hline$\langle\mathrm{oe}\rangle$ & toegeven & zugeben 'to admit' & 0.44 & 4.3 & $\mathrm{t}-\mathrm{z}, \mathrm{v}-\mathrm{b}$ \\
\hline$\langle\mathrm{oe}\rangle$ & vermoeden & vermuten 'to assume' & 0.30 & 3.9 & $\mathrm{~d}-\mathrm{t}$ \\
\hline
\end{tabular}

Cognate fillers

\begin{tabular}{ll}
\hline Stimulus & German cognate 'English translation' \\
\hline hoog & hoch 'high' \\
scheef & schief 'skewed' \\
eeuwig & ewig 'eternal' \\
veertig & vierzig 'forty' \\
slecht & schlecht 'bad'
\end{tabular}


koud

fris

boos

rood

venster

kracht

wereld

jaar

straat

appel

knaap

dochter

gezicht

speler

draad

kist

zweten

komen

streven

regeren

spreken

betalen

zetten

klinken

hopen kalt 'cold'

frisch 'fresh'

böse 'mad'

rot 'red'

Fenster 'window'

Kraft 'power'

Welt 'world'

Jahr 'year'

Strasse 'street'

Apfel 'apple'

Knabe 'lad'

Tochter 'daughter'

Gesicht 'face'

Spieler 'player'

Draht 'wire'

Kiste 'crate'

schwitzen 'to sweat'

kommen 'to come'

streben 'to strive'

regieren 'to govern'

sprechen 'to talk'

bezahlen 'to pay'

setzen 'to put'

klingen 'to sound'

hoffen 'to hope'

Non-cognate fillers

\begin{tabular}{ll}
\hline Stimulus & German translation \\
\hline lelijk (only for $₫ \mathrm{ij}>$ participants) & hässlich 'ugly' \\
misschien & vielleicht 'maybe' \\
stout & unartig 'naughty'
\end{tabular}




\begin{tabular}{ll} 
snoep (only for 〈oe participants) & $\begin{array}{l}\text { Süssigkeiten 'sweets' } \\
\text { Gerhaal }\end{array}$ \\
oorlog & Krieg 'war' \\
toets (only for 〈oe〉 participants) & Test 'test' \\
kijken (only for 〈ij participants) & gucken 'to look' \\
trekken & ziehen 'to pull' \\
snappen & raffen 'to get it' \\
\hline
\end{tabular}

\section{Test stimuli}

Stimuli are in order of appearance for 38 participants and in inverse order of appearance for 42 participants.

\section{Block 1}

\begin{tabular}{|c|c|c|}
\hline Category & Stimulus & German cognate/translation 'English translation' \\
\hline 〈oe〉 cognate & koe & Kuh 'cow' \\
\hline cognate & ranzig & ranzig 'rancid' \\
\hline cognate & bevel & Befehl 'order' \\
\hline$\langle\mathrm{oe}\rangle$ cognate & zoeken & suchen 'to search' \\
\hline cognate & vlieg & Fliege 'fly' \\
\hline cognate & gevaar & Gefahr 'danger' \\
\hline cognate & zaak & Sache 'thing' \\
\hline cognate & koken & kochen 'to cook' \\
\hline non-cognate & ruil & Tausch 'trade' \\
\hline$\langle\mathrm{ij}\rangle$ cognate & vlijtig & fleissig 'industrious' \\
\hline cognate & zon & Sonne 'sun' \\
\hline$\langle\mathrm{oe}\rangle$ cognate & bevoegd & befugt 'authorized' \\
\hline$\langle\mathrm{ij}\rangle$ cognate & mijst [from 'meest'] & meist 'most' \\
\hline$\langle$ 〈oe $\rangle$ cognate & groet & Gruss 'greeting' \\
\hline non-cognate & trui & Pullover 'jumper' \\
\hline$\langle\mathrm{ij}\rangle$ cognate & zwijgen & schweigen 'to be silent' \\
\hline
\end{tabular}




\begin{tabular}{|c|c|c|}
\hline cognate & vlag & Flagge 'flag' \\
\hline cognate & lastig & lästig 'annoying' \\
\hline cognate & actief & aktiv 'active' \\
\hline$\langle i j\rangle$ cognate & rijp & reif 'ripe' \\
\hline cognate & hamer & Hammer 'hammer' \\
\hline cognate & koor & Chor 'choir' \\
\hline cognate & staf & Stab 'rod' \\
\hline cognate & willekeurig & willkürlich 'random' \\
\hline$\langle 0 \mathrm{e}\rangle$ cognate & stoemp [from 'stomp'] & stumpf 'blunt' \\
\hline cognate & woord & Wort 'word' \\
\hline cognate & hemel & Himmel 'heaven' \\
\hline cognate & kerel & Kerl 'fellow' \\
\hline cognate & breken & brechen 'to break' \\
\hline$\langle\mathrm{ij}\rangle$ cognate & smijten & schmeissen 'to throw' \\
\hline cognate & plicht & Pflicht 'duty' \\
\hline cognate & stem & Stimme 'voice' \\
\hline cognate & zeer & sehr 'very' \\
\hline cognate & antwoord & Antwort 'answer' \\
\hline non-cognate & wet & Gesetz 'law' \\
\hline cognate & plannen & planen 'to plan' \\
\hline cognate & dragen & tragen 'to carry' \\
\hline$\langle$ oe $\rangle$ cognate & doen & tun 'to do' \\
\hline cognate & snel & schnell 'fast' \\
\hline$\langle i j\rangle$ cognate & wijze & Weise 'manner' \\
\hline cognate & dik & dick 'thick' \\
\hline$\langle\mathrm{oe}\rangle$ cognate & oeverloos & uferlos 'boundless' \\
\hline cognate & kletsen & klatschen 'to chitchat' \\
\hline$\langle\mathrm{ij}\rangle$ cognate & schijf & Scheibe 'disk' \\
\hline cognate & arts & Artz 'physician' \\
\hline cognate & zinvol & sinnvoll 'sensible' \\
\hline non-cognate & bedoelen & meinen 'to mean' \\
\hline
\end{tabular}




\begin{tabular}{lll} 
cognate & water & Wasser 'water' \\
non-cognate & gezin & Familie 'family' \\
non-cognate & hesp & Schinken 'ham' \\
\hline
\end{tabular}

Block 2

\begin{tabular}{|c|c|c|}
\hline Category & Stimulus & German cognate/translation 'English translation' \\
\hline$\langle\mathrm{oe}\rangle$ cognate & soep & Suppe 'soup' \\
\hline cognate & verbrand & verbrennt 'burned' \\
\hline cognate & laten & lassen 'let' \\
\hline$\langle\mathrm{oe}\rangle$ cognate & hoed & Hut 'hat' \\
\hline 〈ij〉 cognate & knijpen & kneifen 'to pinch' \\
\hline cognate & zweven & schweben 'to hover' \\
\hline cognate & zwaar & schwer 'heavy' \\
\hline cognate & identiek & identisch 'identical' \\
\hline$\langle\mathrm{oe}\rangle$ cognate & proesten & prusten 'to snort' \\
\hline cognate & braaf & brav 'well-behaved' \\
\hline cognate & bloot & bloss 'naked' \\
\hline$\langle\mathrm{oe}\rangle$ cognate & vloeken & fluchen 'to swear' \\
\hline \multirow[t]{2}{*}{$\langle\mathrm{ij}\rangle$ cognate } & ijnzaam [from & einsam 'lonely' \\
\hline & ‘eenzaam’] & \\
\hline 〈oe〉 cognate & doek & Tuch 'cloth' \\
\hline cognate & kloppen & klopfen 'to knock' \\
\hline cognate & bed & Bett 'bed' \\
\hline 〈oe〉 cognate & doenker [from 'donker'] & dunkel 'dark' \\
\hline cognate & positie & Position 'position' \\
\hline$\langle i j\rangle$ cognate & brijd [from 'breed'] & breit 'broad' \\
\hline non-cognate & vertalen & übersetzen 'to translate' \\
\hline cognate & houden & halten 'to hold' \\
\hline$\langle\mathrm{oe}\rangle$ cognate & boek & Buch 'book' \\
\hline cognate & sleutel & Schlüssel 'key’ \\
\hline
\end{tabular}




\begin{tabular}{|c|c|c|}
\hline$\langle\mathrm{ij}\rangle$ cognate & bewijzen & beweisen 'to proof' \\
\hline non-cognate & praten & reden 'to talk' \\
\hline cognate & hertog & Herzog 'duke' \\
\hline cognate & vader & Vater 'father' \\
\hline cognate & meten & messen 'to measure' \\
\hline cognate & varen & fahren 'to sail' \\
\hline$\langle i j\rangle$ cognate & schrijven & schreiben 'to write' \\
\hline non-cognate & duit & Kies 'dough (money)' \\
\hline cognate & controle & Kontrolle 'control' \\
\hline cognate & fles & Flasche 'bottle' \\
\hline cognate & hart & Herz 'heart' \\
\hline$\langle i j\rangle$ cognate & pijl & Pfeil 'arrow' \\
\hline cognate & plegen & pflegen 'to care for' \\
\hline cognate & dak & Dach 'roof' \\
\hline$\langle\mathrm{ij}\rangle$ cognate & slijm & Schleim 'slime' \\
\hline cognate & beter & besser 'better' \\
\hline cognate & aarde & Erde 'earth' \\
\hline cognate & veel & viel 'much' \\
\hline cognate & begraven & begraben 'to bury' \\
\hline cognate & kennis & Kenntnis 'knowledge' \\
\hline cognate & zeker & sicher 'sure' \\
\hline cognate & voorwaarts & vorwärts 'forward' \\
\hline cognate & maken & machen 'to make' \\
\hline non-cognate & gek & verrückt 'insane' \\
\hline non-cognate & stipt & pünktlich 'punctual' \\
\hline non-cognate & spijbelen & schwänzen 'to bunk off' \\
\hline
\end{tabular}

Block 3

\begin{tabular}{lll}
\hline Category & Stimulus & German cognate/translation 'English translation' \\
\hline cognate & vak & Fach 'subject'
\end{tabular}




\begin{tabular}{|c|c|c|}
\hline 〈oe〉 cognate & stoel & Stuhl 'chair' \\
\hline$\langle\mathrm{ij}\rangle$ cognate & ijzer & Eisen 'iron' \\
\hline cognate & prins & Prinz 'prince' \\
\hline 〈oe〉 cognate & schoen & Schuh 'shoe' \\
\hline cognate & zitten & sitzen 'to sit' \\
\hline cognate & geweld & Gewalt 'violence' \\
\hline cognate & kroon & Krone 'crown' \\
\hline 〈oe〉 cognate & groep & Gruppe 'group' \\
\hline cognate & overigens & übrigens 'incidentally' \\
\hline cognate & geluk & Glück 'luck' \\
\hline non-cognate & broek & Hose 'trousers' \\
\hline cognate & dwingen & zwingen 'to force' \\
\hline cognate & liever & lieber 'rather' \\
\hline$\langle\mathrm{ij}\rangle$ cognate & tijd & Zeit 'time' \\
\hline cognate & verliezen & verlieren 'to lose' \\
\hline non-cognate & grap & Witz 'joke' \\
\hline cognate & sterven & sterben 'to die' \\
\hline cognate & plant & Pflanze 'plant' \\
\hline$\langle i j\rangle$ cognate & bijten & beissen 'to bite' \\
\hline cognate & donderdag & Donnerstag 'Thursday' \\
\hline cognate & zegen & Segen 'blessing' \\
\hline cognate & veranderen & verändern 'to change' \\
\hline$\langle i j\rangle$ cognate & hijt [from 'heet'] & heiss 'hot' \\
\hline cognate & stad & Stadt 'city' \\
\hline non-cognate & leuk & toll 'great' \\
\hline non-cognate & kiezen & wählen 'to choose' \\
\hline$\langle\mathrm{ij}\rangle$ cognate & zwijn & Schwein 'pig' \\
\hline cognate & laatst & letzt 'last' \\
\hline 〈oe〉 cognate & poetsen & putzen 'to clean' \\
\hline cognate & afstand & Abstand 'distance' \\
\hline cognate & pakken & packen 'to pack' \\
\hline
\end{tabular}




\begin{tabular}{lll} 
cognate & nat & nass 'wet' \\
cognate & zinken & sinken 'to sink' \\
cognate & zeggen & sagen 'to say' \\
cognate & slank & schlank 'slim' \\
cognate & gebied & Gebiet 'area' \\
cognate & overdreven & übertrieben 'exaggerated' \\
〈oe cognate & hoesten & husten 'to cough' \\
$\langle$ ij〉 cognate & abdij & Abtei 'abbey' \\
non-cognate & duf & muffig 'musty' \\
〈oe cognate & gezoend [from 'gezond'] & gesund 'healthy' \\
cognate & compleet & komplett 'complete' \\
cognate & openen & öffnen 'to open' \\
$\langle i j\rangle$ cognate & strijd & Streit 'fight' \\
non-cognate & blij & froh 'happy' \\
$\langle$ oè cognate & moenter [from 'monter'] & munter 'cheerful' \\
cognate & willen & wollen 'to want' \\
cognate & wapen & Waffen 'weapon' \\
\hline
\end{tabular}

